\title{
Targeted delivery of paclitaxel and doxorubicin to cancer xenografts via the nanoparticle of nano- diamino-tetrac
}

This article was published in the following Dove Press journal:

International Journal of Nanomedicine

15 February 2017

Number of times this article has been viewed

\author{
Thangirala Sudha' \\ Dhruba J Bharali' \\ Murat Yalcin ${ }^{1,2}$ \\ Noureldien HE Darwish ${ }^{1,3}$ \\ Melis Debreli Coskun 1,4 \\ Kelly A Keating' \\ Hung-Yun $\operatorname{Lin}^{5,6}$ \\ Paul J Davis ${ }^{1,7}$ \\ Shaker A Mousa' \\ 'The Pharmaceutical Research \\ Institute, Albany College of Pharmacy \\ and Health Sciences, Rensselaer, NY, \\ USA; 'Department of Physiology, \\ Veterinary Medicine Faculty, Uludag \\ University, Gorukle, Bursa, Turkey; \\ ${ }^{3}$ Department of Clinical Pathology, \\ Faculty of Medicine, Mansoura \\ University, Mansoura, Egypt; \\ ${ }^{4}$ Department of Biology, Faculty of \\ Arts and Sciences, Uludag University, \\ Gorukle, Bursa, Turkey; ${ }^{5} \mathrm{PhD}$ Program \\ for Cancer Biology and Drug \\ Discovery, College of Medical Science \\ and Technology, ${ }^{6}$ Taipei Cancer Center, \\ Taipei Medical University, Taipei, Taiwan; \\ ${ }^{7}$ Department of Medicine, Albany \\ Medical College, Albany, NY, USA
}

Correspondence: Shaker A Mousa The Pharmaceutical Research Institute, Albany College of Pharmacy and Health Sciences, I Discovery Drive, Rensselaer, NY I 2144 , USA

Tel +I 5186947397

Fax + I 5186947567

Email shaker.mousa@acphs.edu
Abstract: The tetraiodothyroacetic acid (tetrac) component of nano-diamino-tetrac (NDAT) is chemically bonded via a linker to a poly(lactic-co-glycolic acid) nanoparticle that can encapsulate anticancer drugs. Tetrac targets the plasma membrane of cancer cells at a receptor on the extracellular domain of integrin $\alpha v \beta 3$. In this study, we evaluate the efficiency of NDAT delivery of paclitaxel and doxorubicin to, respectively, pancreatic and breast cancer orthotopic nude mouse xenografts. Intra-tumoral drug concentrations were 5-fold (paclitaxel; $P<0.001$ ) and 2.3-fold (doxorubicin; $P<0.01$ ) higher than with conventional systemic drug administration. Tumor volume reductions reflected enhanced xenograft drug uptake. Cell viability was estimated by bioluminescent signaling in pancreatic tumors and confirmed an increased paclitaxel effect with drug delivery by NDAT. NDAT delivery of chemotherapy increases drug delivery to cancers and increases drug efficacy.

Keywords: doxorubicin, integrin, nanoparticle, Nanotetrac, NDAT, paclitaxel, tetraiodothyroacetic acid, xenografts

\section{Introduction}

Generic cancer chemotherapeutic agents in use today act by a number of mechanisms. ${ }^{1-5}$ They destroy cell DNA, inhibit synthesis of nucleic acid components that make up DNA and RNA, disrupt gene transcription of specific RNAs, or they inhibit protein synthesis. Doxorubicin is an example of an anticancer agent that disorders gene transcription of specific RNAs, ${ }^{3}$ and paclitaxel is a protein synthesis inhibitor. ${ }^{4}$ These various drug effects are not limited to cancer cells, and thus the generic anticancer drugs act on nonmalignant cells to generate important side effects. Because of the side effect profiles of generic cancer chemotherapeutic agents, there is substantial interest in developing molecular mechanisms that direct these drugs specifically to cancer cells. ${ }^{6-11}$

Tetraiodothyroacetic acid (tetrac) is a ligand of a specific target on the extracellular domain of plasma membrane integrin $\alpha v \beta 3,{ }^{12}$ an integrin generously expressed by cancer cells and by dividing endothelial cells of tumor-relevant blood vessels. We have covalently bonded tetrac via a short diaminopropane linker to a $150-200 \mathrm{~nm}$ poly(lactic-co-glycolic acid) (PLGA) nanoparticle (Nanotetrac, nano-diamino-tetrac [NDAT]), as shown in Figure 1. The nanoparticle of NDAT can encapsulate a chemotherapeutic drug payload ${ }^{13}$ to offer tumor-targeted drug delivery and the prospect of decreased systemic toxicity. The substantial progress made elsewhere in the development of targeted PLGA-based anticancer drug delivery systems has been reviewed by van der Meel et al ${ }^{14}$ and Iyer et al. ${ }^{15}$ Recently described cancer cell-targeting moieties 


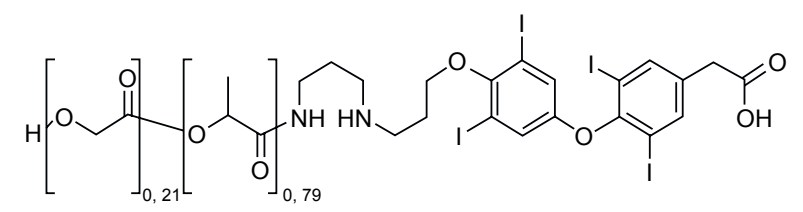

Figure I Chemical structure of NDAT (Nanotetrac).

Note: The chemical name is $\{4-[4-(3-(3-(p o l y-2-(2-h y d r o x y a c e t o t o x y))$ propanamido) aminopropoxy)-3,5-diiodophenoxy]-3,5-diiodopheny\} acetic acid.

Abbreviations: NDAT, nano-diamino-tetrac; tetrac, tetraiodothyroacetic acid.

bound to PLGA include folate antennae, ${ }^{16,17}$ DNA antibody, ${ }^{18}$ transferrin, ${ }^{19}$ chemokine-targeting peptide, ${ }^{20}$ modified epidermal growth factor (EGF), ${ }^{21}$ and arginine-glycine-aspartic acid (RGD) peptide. ${ }^{22}$ In a companion article, ${ }^{23}$ we report the use of this delivery system to enhance cisplatin uptake by tumor xenografts and to reduce cisplatin-induced neurotoxicity.

In the current study, we examine the tumor xenograftspecific delivery of paclitaxel and doxorubicin by NDAT. Chemotherapy with these 2 agents has been of interest in hepatocellular carcinoma ${ }^{24}$ and lung cancer, ${ }^{25}$ and both agents, in contrast to cisplatin, are ligands of P-glycoprotein (P-gp). P-gp is a plasma membrane efflux pump that is a component of cancer cell chemoresistance and is subject to inhibition by tetrac. ${ }^{26,27}$

\section{Methods}

\section{Generation of free PLGA nanoparticles encapsulated with paclitaxel or doxorubicin}

The methodology was based on prior publications and involves a single solvent emulsion in the presence of the chemotherapeutic agent. ${ }^{13,28,29}$ The PLGA nanoparticles obtained were characterized in terms of size, surface charge, and loading as described in the following sections.

\section{Dynamic light scattering (DLS)}

The size distribution of the synthesized nanoparticles in aqueous dispersions was determined using a Malvern zeta sizer (Malvern Instrumentation Co, Westborough, MA, USA). Approximately $1 \mathrm{~mL}$ of the nanoparticle solution was pipetted into a $3 \mathrm{~mL}, 4$-sided, clear plastic cuvette and measured directly.

\section{Encapsulation of paclitaxel or doxorubicin in the PLGA of NDAT}

The generation of NDAT that contains an encapsulated anticancer drug was modified from published methods. ${ }^{13,28}$ The optimized method of adsorption of chemotherapeutic agent to PLGA (Evonik Industries, Birmingham, AL, USA) in NDAT involved $100 \mathrm{mg}$ PLGA conjugated to tetrac (DPx Fine Chemicals, Regensburg, Germany) to which was added
$500 \mu \mathrm{L}$ of chemotherapeutic drug (dissolved as $10 \mathrm{mg} / \mathrm{mL}$ in ethyl acetate). Five $\mathrm{mL}$ of $1 \%$ poly(vinyl alcohol) (PVA) was then added, and the resultant mixture was sonicated intermittently for $90 \mathrm{~s}$. Ten $\mathrm{mL}$ of $0.05 \%$ PVA was added, and the mixture was sonicated for $1 \mathrm{~min}$. The ethyl acetate was removed with dialysis against $12 \mathrm{kDa}$ cutoff membrane dialysis tubing. The water was changed several times. The entire solution was freeze-dried using a 2:1 sucrose solution and redispersed in water. Resulting nanoparticles (NDAT with encapsulated payload) were characterized in terms of size and surface charge using DLS. The amount of paclitaxel and doxorubicin encapsulated in the nanoparticles was determined by disintegrating the nanoparticles and using ultraviolet (UV)-visible spectroscopy to measure paclitaxel (absorbance at $239 \mathrm{~nm}$ ) or doxorubicin (absorbance at $500 \mathrm{~nm}$ ) compared to standard curves for drug concentrations (Figures S1-S3). The entrapment efficiency was determined using the following formula:

$$
\text { Entrapment efficiency }(\text { loading })=\frac{[\text { Drug }]_{\mathrm{f}}}{[\text { Drug }]_{t}} \times 100
$$

where $[\text { Drug }]_{\mathrm{f}}$ is the concentration of paclitaxel or doxorubicin in the nanoparticles and $[\mathrm{Drug}]_{\mathrm{t}}$ is the theoretical concentration of drug (ie, the total amount of paclitaxel or doxorubicin added initially). The loading (w/w) was determined by weighing the total amount of nanoformulations on a balance and determining the corresponding amount of doxorubicin or paclitaxel with UV/visible spectroscopy.

\section{Cell culture}

Pancreatic cancer SUIT2-luc cells (generous gift from MD Anderson Cancer Center, Houston, TX, USA) and breast cancer SUM149PT cells (ATCC, Manassas, VA, USA) were grown in Dulbecco's Modified Eagle's Medium (DMEM) supplemented with 10\% fetal bovine serum, 1\% penicillin, and $1 \%$ streptomycin. Cells were cultured at $37^{\circ} \mathrm{C}$ to sub-confluence and treated with $0.25 \%(\mathrm{w} / \mathrm{v})$ trypsin/ ethylenediaminetetraacetic acid (EDTA) to induce cell release from culture flask. The cells were washed with culture medium, suspended in DMEM that was free of phenol red and fetal bovine serum, and counted.

\section{Animals and xenografts}

Immunodeficient female $\mathrm{NCr}$ nude homozygous mice aged 5-6 weeks weighing between 18 and $20 \mathrm{~g}$ were purchased from Harlan Laboratories (Somerset, NJ, USA). All animal studies were conducted at the animal facility of the Veteran Affairs Medical Center (Albany, NY, USA) in accordance 
with and approved by the IACUC of the Veterans Affairs Medical Center (Albany, NY) and their current institutional guidelines for humane animal treatment. Mice were maintained under specific pathogen-free conditions and housed under controlled conditions of temperature $\left(20^{\circ} \mathrm{C}-24^{\circ} \mathrm{C}\right)$ and humidity $(60 \%-70 \%)$ and $12 \mathrm{~h}$ light/dark cycle with ad libitum access to water and food. Mice were allowed to acclimatize for 5 days before the study.

\section{Pancreatic cancer xenografts}

For the orthotopic pancreatic tumor model, SUIT2-luc cells were harvested $\left(2 \times 10^{5}\right.$ cells per mouse, suspended in $30 \mu \mathrm{L}$ of DMEM) and injected into the pancreas of anesthetized mice. Immediately before the initiation of treatment, animals were randomized into 6 groups (8-9 animals/group) by tumor mass detected with an in vivo imaging system $\left(\right.$ IVIS $^{\circledR}$; Perkin Elmer, Boston, MA, USA). The 6 treatments were as follows: control (phosphate-buffered saline, PBS), paclitaxel (0.3 mg/kg body weight [b.w.]), void PLGA nanoparticles, PLGA-paclitaxel (paclitaxel encapsulated in PLGA nanoparticles, $0.3 \mathrm{mg} / \mathrm{kg}$ b.w.), NDAT (0.3 mg/kg b.w.), and NDAT-paclitaxel (NDAT, $0.3 \mathrm{mg} / \mathrm{kg}$ b.w., with a PLGA payload of paclitaxel, $0.3 \mathrm{mg} / \mathrm{kg}$ b.w.). All treatments were begun 2 days after tumor cell implantation and administered subcutaneously (s.c.) daily for 21 days.

Orthotopic tumor volume was estimated weekly by caliper estimation of xenograft diameter. SUIT2-luc tumor-bearing mice were injected s.c. with $50 \mu \mathrm{L}$ D-luciferin $(30 \mathrm{mg} / \mathrm{mL})$. Mice were anesthetized using isoflurane, and post luciferin administration mice were imaged in the IVIS system. Photographic and luminescence images were taken at constant exposure time. Xenogen IVIS Living Image software (version 3.2) was used to quantify non-saturated bioluminescence in regions of interest (ROI). Light emission between $5.5 \times 10^{6}$ and $7.0 \times 10^{10}$ photons/s was assumed to be indicative of viable luciferase-labeled tumor cells, while emissions below this range were considered as background. Bioluminescence was quantified as photons/s for each ROI. In vivo tumor kinetic growth and metastasis were monitored by signal intensity. Ex vivo tumor imaging was performed to confirm the signal intensity in the tumors after termination of the study.

\section{Breast cancer xenografts}

For the orthotopic breast tumor model, SUM149PT invasive ductal breast cancer cells were implanted $\left(4 \times 10^{6}\right.$ cells in $100 \mu \mathrm{L}$ DMEM, 50\% Matrigel $^{\circledR}$ ) into 2 abdominal mammary pads of the mice. Immediately before treatment was initiated, animals were randomized into 6 groups ( 5 per group) by tumor volume measured with Vernier calipers. The 6 treatments were as follows: control (PBS), doxorubicin (1 mg/kg b.w.), void PLGA nanoparticles, PLGA-doxorubicin (doxorubicin encapsulated into PLGA nanoparticles, $1 \mathrm{mg} / \mathrm{kg}$ b.w.), NDAT $(0.3 \mathrm{mg} / \mathrm{kg})$, and NDAT-doxorubicin (NDAT, $0.3 \mathrm{mg} / \mathrm{kg}$ b.w., with a PLGA payload of doxorubicin, $1 \mathrm{mg} / \mathrm{kg}$ b.w.). All treatments were begun after detection of palpable tumor mass (4-5 days) and administered s.c. daily for 21 days. Tumor size was measured weekly with calipers.

\section{Measurement of tumor content of chemotherapeutic agent with liquid chromatography-mass spectroscopy/mass spectroscopy (LC-MS/MS)}

Stock solutions, working solutions, and calibration

curve

Working solutions of paclitaxel to make a calibration curve were prepared with $70 \%$ acetonitrile and $0.1 \%$ formic acid at concentrations of $0.97,1.95,3.9,7.81,15.6,31.25,62.5,125$, 250,500 , and $1,000 \mathrm{ng} / \mathrm{mL}$. The internal standard, docetaxel, was prepared with $70 \%$ acetonitrile and $0.1 \%$ formic acid at a concentration of $20 \mathrm{ng} / \mathrm{mL}$. Working solutions of doxorubicin to make a calibration curve were prepared with $70 \%$ acetonitrile at concentrations of $0.78,1.56,3.12,6.25,12.5$, $25,50,75,100,200,300,400$, and $500 \mathrm{ng} / \mathrm{mL}$. The internal standard, reserpine, was prepared with $70 \%$ acetonitrile at a concentration of $20 \mathrm{ng} / \mathrm{mL}$.

\section{Tissue sample preparation}

To measure the paclitaxel content of pancreatic tumors, $100 \mu \mathrm{L}$ of homogenized tissue, $20 \mu \mathrm{L}$ of internal standard docetaxel, and $0.8 \mathrm{~mL}$ of tetra-butyl methyl ether were added and mixed for $10 \mathrm{~min}$. After centrifugation for $5 \mathrm{~min}$ at $16,000 \mathrm{rpm}$, the supernatant was collected and dried under $\mathrm{N}_{2}$. The residue was reconstituted with $1.0 \mathrm{~mL}$ of acetonitrile $(70 \%$ in $0.1 \%$ formic acid) for LC-MS/MS analysis. To measure the doxorubicin content of breast cancer tumors, a modification of the method of Israel et $\mathrm{al}^{30}$ was used. Borate buffer $(100 \mu \mathrm{L}, 0.5 \mathrm{M}$, pH 9.8), $1.2 \mathrm{~mL}$ methanol:chloroform (1:4), and internal standard (reserpine) were added to $200 \mu \mathrm{L}$ of tissue homogenate and mixed for $20 \mathrm{~min}$. After centrifugation for $10 \mathrm{~min}$ at $4^{\circ} \mathrm{C}$ at $10,000 \mathrm{rpm}$, the lower organic layer was collected and dried by vacuum centrifugation. Dried samples were reconstituted with $150 \mu \mathrm{L}$ of $70 \%$ acetonitrile for LC-MS/MS analysis.

\section{LC-MS/MS analysis}

LC-MS/MS analysis was performed on an API 4000 Triple Quad mass spectrometer (Applied Biosystem MDS Sciex, Toronto, ON, Canada) using Analyst 1.62 control software and configured with a Shimadzu LC-20AD pumping system, 
a SIL-20AC auto sampler, and CTO-20AC column oven. The instrument was operated in a positive ion mode with a turbo $\mathrm{V}$ electrospray source. All calibration curves were plotted using linear regression with a weight factor of $1 / x$. For both paclitaxel and doxorubicin, chromatographic separation was performed on a Waters CORTECS C 18 column $(2.1 \times 50 \mathrm{~mm}$, $2.7 \mu \mathrm{m}$ particles). The mobile phase consisted of solvent $\mathrm{A}$ ( $8 \mathrm{mM}$ ammonium formate with $0.15 \%$ formic acid) and solvent B (100\% acetonitrile $+0.1 \%$ formic acid $[\mathrm{v} / \mathrm{v}])$. Samples were eluted at a flow rate of $0.30 \mathrm{~mL} / \mathrm{min}$ with $25 \%$ B for $1 \mathrm{~min}$, then $0.1 \mathrm{~min}$ to $90 \% \mathrm{~B}$ and held for $1.5 \mathrm{~min}$. Total run time was $4 \mathrm{~min}$. Column oven temperature was kept at $40^{\circ} \mathrm{C}$, and sample injection volume was $10 \mu \mathrm{L}$. For paclitaxel, the multiple reaction monitoring (MRM) transition for the analyte was $m / z 871.5>286.1$, and for internal standard it was $m / z 808.3>527.0$. Operation parameters were as follows: curtain gas, $25 \mathrm{psi}$; heated nebulizer temperature, $420^{\circ} \mathrm{C}$; ion spray voltage, $4,500 \mathrm{~V}$; gas 1 , 70 psi; gas 2, 40 psi; declustering potential, $41 \mathrm{~V}$ (paclitaxel), $13 \mathrm{~V}$ (docetaxel); entrance potential [EP], $10 \mathrm{~V}$; collision energy [CE], $35 \mathrm{~V}$ (paclitaxel), $17 \mathrm{~V}$ (docetaxel); collision cell exit potential [CXP], $12 \mathrm{~V}$ (paclitaxel), $22 \mathrm{~V}$ (docetaxel); and collisionally activated dissociation [CAD] gas, 4.0 psi. Dwell time for each transition was $120 \mathrm{~ms}$. For doxorubicin, the MRM transition for the analyte was $m / z 544.2>397.1$ and for internal standard it was $m / z 609.4>195$, and the operation parameters were as follows: curtain gas, 20 psi; heated nebulizer temperature, $450^{\circ} \mathrm{C}$; ion spray voltage, $5,100 \mathrm{~V}$; gas $1,60 \mathrm{psi}$; gas $2,55 \mathrm{psi}$; declustering potential, $52 \mathrm{~V}$ (doxorubicin), $71 \mathrm{~V}$ (reserpine); EP, $10 \mathrm{~V}$; CE, $17 \mathrm{~V}$ (doxorubicin), $51 \mathrm{~V}$ (reserpine); CXP, $12 \mathrm{~V}$ (doxorubicin), $14 \mathrm{~V}$ (reserpine); and CAD gas, $5.0 \mathrm{~V}$. Dwell time for each transition was $120 \mathrm{~ms}$.

\section{Statistical analysis}

Statistical analysis was performed using one-way ANOVA and comparing the mean \pm standard error of the mean (SEM)
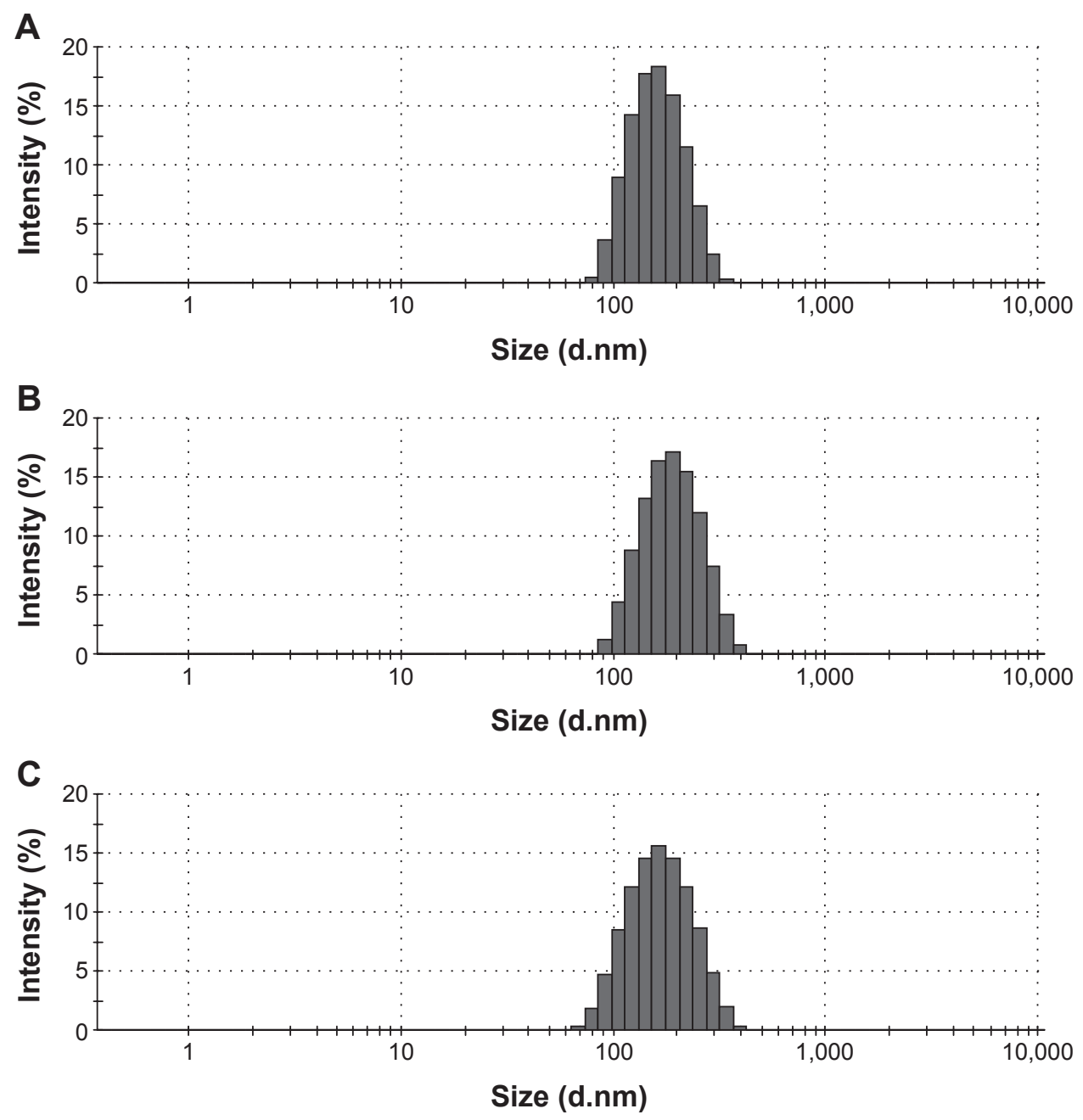

Figure 2 Size measurement of nanoparticles using DLS.

Notes: (A) NDAT (nanoparticulate tetrac). (B) NDAT-paclitaxel, (C) NDAT-doxorubicin. Average particle size ranged from I75 to $210 \mathrm{~nm}$. Abbreviations: DLS, dynamic light scattering; NDAT, nano-diamino-tetrac; tetrac, tetraiodothyroacetic acid. 

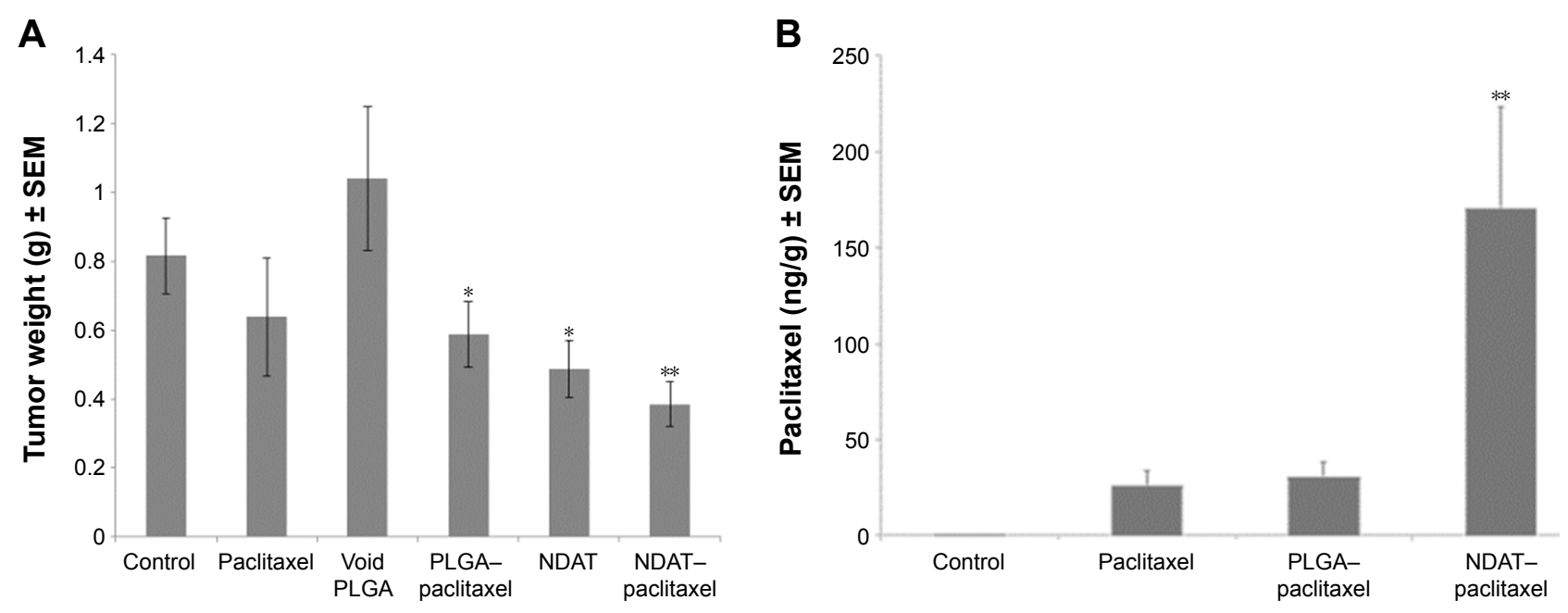

Figure 3 Effect on tumors of pancreatic SUIT2-luc cancer cell xenografts of daily s.c. administration of control (PBS), paclitaxel, void PLGA, PLGA-paclitaxel (paclitaxel encapsulated in PLGA nanoparticles, without tetrac), low-dose NDAT ( $0.3 \mathrm{mg} / \mathrm{kg}$ b.w., with empty payload compartment), and NDAT ( $0.3 \mathrm{mg} / \mathrm{kg}$ b.w.)-paclitaxel ( $0.3 \mathrm{~kg} / \mathrm{mg}$ b.w.).

Notes: (A) Tumor weights: weights were measured of harvested grafts at animal sacrifice. Significant tumor weight reduction was achieved with PLGA-paclitaxel, NDAT, and NDAT-paclitaxel. $n=8-9$ mice per group, ${ }^{* P}<0.01$ vs void PLGA, ${ }^{* * P}<0.001$ vs void PLGA or NDAT-paclitaxel. (B) Paclitaxel uptake by pancreatic cancer tumors in response to administration of control (PBS), paclitaxel, PLGA-paclitaxel, and NDAT-paclitaxel measured with LC-MS/MS. Tumor content of paclitaxel in grafts exposed to NDAT-paclitaxel was 5.2-fold that achieved with paclitaxel treatment alone or PLGA-paclitaxel. $* * P<0.001$ vs paclitaxel and PLGA-paclitaxel.

Abbreviations: b.w., body weight; LC-MS/MS, liquid chromatography-mass spectroscopy/mass spectroscopy; NDAT, nano-diamino-tetrac; PBS, phosphate-buffered saline; PLGA, poly(lactic-co-glycolic acid); s.c., subcutaneous; SEM, standard error of the mean; tetrac, tetraiodothyroacetic acid.

from each experimental group with its respective control group. Statistical differences approaching $P<0.05$ were considered statistically significant.

\section{Results}

\section{Nanoparticle characterization and chemotherapeutic agent entrapment and loading efficiency}

The average nanoparticle size $(\mathrm{nm})$ for the different NDAT formulations encapsulating paclitaxel or doxorubicin measured with DLS was $\sim 200 \mathrm{~nm}$ (Figure 2B and C). The average size for the different PLGA nanoparticles encapsulating paclitaxel or doxorubicin was $<200 \mathrm{~nm}$ (Figure S4). The entrapment efficiency of the nanoparticles was $\sim 65 \%$ for doxorubicin and $80 \%$ for paclitaxel. The nanoparticle loading for doxorubicin was $2.6 \% \mathrm{w} / \mathrm{w}$, and for paclitaxel it was $\sim 3.1 \% \mathrm{w} / \mathrm{w}$.

\section{Anticancer efficacy and tumor uptake of chemotherapeutic agents \\ Pancreatic cancer xenografts and PLGA-paclitaxel or NDAT-paclitaxel}

Figure $3 \mathrm{~A}$ shows the effects of treatments on tumor weight at the time of animal sacrifice. NDAT-paclitaxel reduced tumor
A

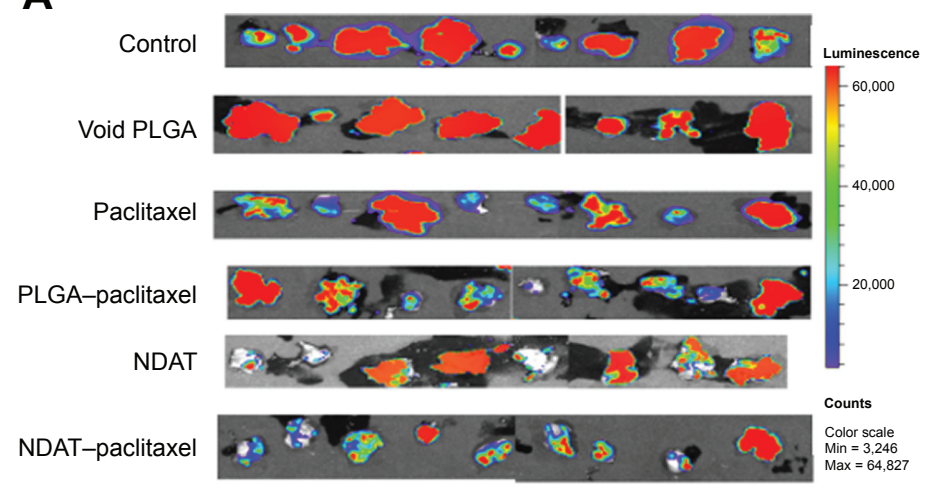

B

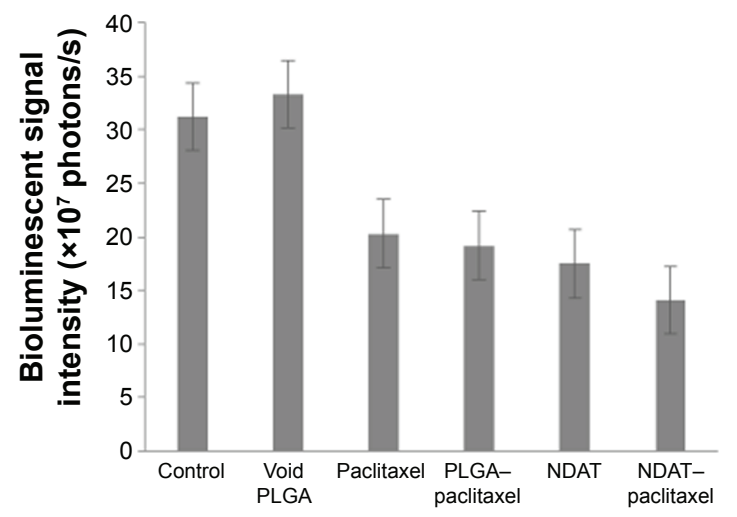

Figure 4 Estimation of cancer cell viability in harvested tumors with IVIS imaging of SUIT2-luc tumor bioluminescence at study conclusion (day 2 I).

Notes: Loss of viability is prominent in cells exposed to NDAT-paclitaxel and to PLGA-paclitaxel (paclitaxel encapsulated in unmodified PLGA nanoparticles). (A) IVIS images, vertical luminescence color bar (right margin) estimates viability, ranging from nonviable (blue) to fully viable (red). (B) Bioluminescent signal intensity of pancreatic orthotopic xenografts.

Abbreviations: IVIS, in vivo imaging system; NDAT, nano-diamino-tetrac; PLGA, poly(lactic-co-glycolic acid); tetrac, tetraiodothyroacetic acid. 
weight by $65 \%$ compared to void nanoparticle control and by $55 \%$ vs vehicle control $(P<0.001)$. The reduction compared to paclitaxel alone was 39\%. Submaximal doses of NDAT (no paclitaxel) had a significant antitumor effect on tumor weight (55\% vs void PLGA nanoparticle control; $P<0.01$ ). Figure $3 \mathrm{~B}$ shows the tumor content of paclitaxel achieved with paclitaxel alone, PLGA-paclitaxel, and NDAT-paclitaxel as measured with LC-MS/MS. Paclitaxel uptake by tumors from NDAT-paclitaxel was increased 5.2-fold over paclitaxel alone and PLGA-paclitaxel $(P<0.001)$. Orthotopic tumor bioluminescent signaling of SUIT2-luc tumors at animal termination (day 21) is shown in Figure 4. In addition to the tumor shrinkage achieved by NDAT-paclitaxel (Figure 3A), a clear trend in the reduction in tumor cell viability measured with IVIS reveals a trend in advantage of NDAT-paclitaxel over other drug formulations despite the small tumor size (Figure 4).

\section{Breast cancer xenografts and PLGA-doxorubicin or NDAT-doxorubicin}

Progressive effects of various treatments on breast cancer (SUM149PT) tumor volumes are shown in Figure 5A. Control tumors (vehicle, void nanoparticles) grew vigorously. Suboptimal dosing of NDAT alone and of PLGAdoxorubicin and NDAT-doxorubicin were equally effective in suppressing the growth of tumor. These effects were supported by measurements of tumor weight at animal sacrifice (Figure 5B). Despite the similar effects on tumor volume and weight of the various drug combinations, there
A

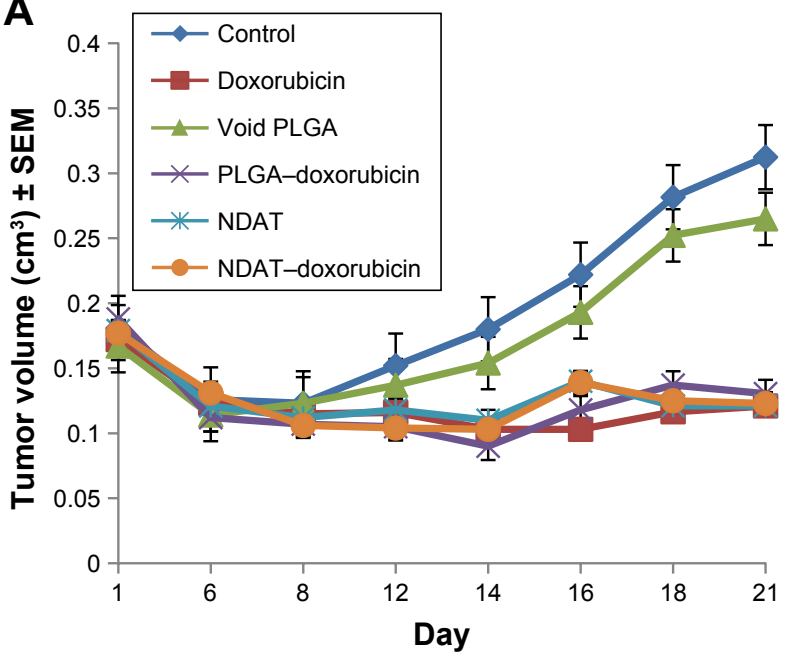

B

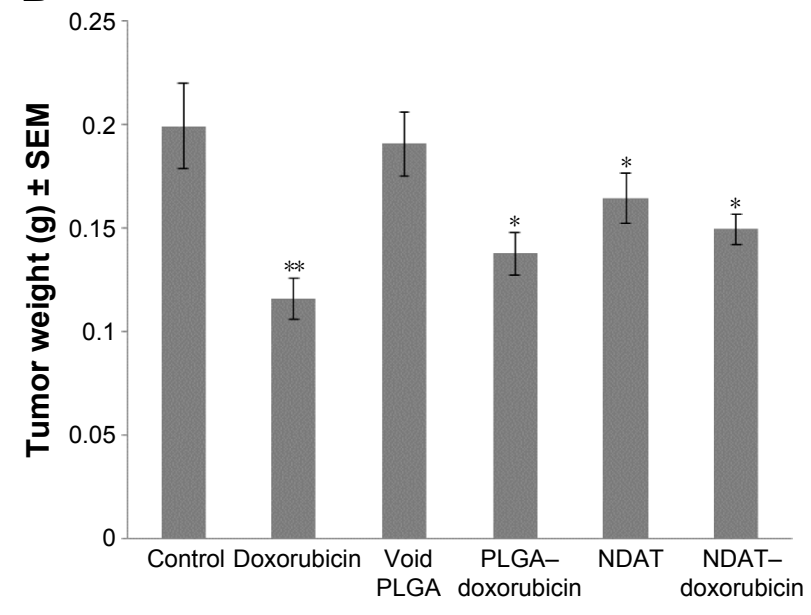

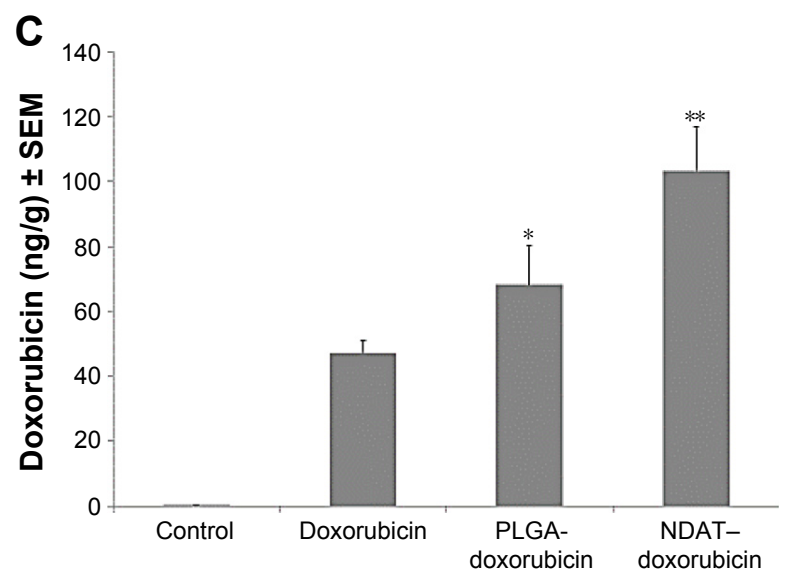

Figure 5 Effects on tumors of breast cancer SUMI49PT cell xenografts of daily s.c. administration of control (PBS), doxorubicin, void PLGA, PLGA-doxorubicin (doxorubicin encapsulated in PLGA nanoparticles, without tetrac), low-dose NDAT (0.3 mg/kg, with empty payload compartment), and NDAT (0.3 mg/kg b.w.)-doxorubicin (I mg/kg), for $n=5$ mice per group.

Notes: (A) Tumor volumes: volumes were estimated from caliper measurements. (B) Tumor weights: weights were measured of harvested tumors at animal sacrifice. $* P<0.05$ vs void PLGA, ${ }^{* * P}<0.0$ I vs control. (C) Doxorubicin uptake by breast cancer tumors in response to administration of control (PBS), doxorubicin, PLGA-doxorubicin, and NDAT-doxorubicin measured with LC-MS/MS. NDAT-doxorubicin caused a 2.3 -fold increase in tumor doxorubicin content, compared to conventional doxorubicin administration. NDAT-doxorubicin achieved a $40 \%$ higher tumor content of chemotherapeutic agent than PLGA-doxorubicin. $* P<0.05$ vs doxorubicin, $* * P<0.0$ I vs doxorubicin and PLGA-doxorubicin.

Abbreviations: b.w., body weight; NDAT, nano-diamino-tetrac; PBS, phosphate-buffered saline; PLGA, poly(lactic-co-glycolic acid); s.c., subcutaneous; SEM, standard error of the mean; tetrac, tetraiodothyroacetic acid. 
were significant differences in tumor accumulation of doxorubicin depending on the presentation of the drug to the tumors. Figure $5 \mathrm{C}$ shows the tumor content of doxorubicin achieved with doxorubicin alone, PLGA-doxorubicin, and NDAT-doxorubicin. The loading of doxorubicin into NDAT (NDAT-doxorubicin) resulted in a 2.3-fold increase in chemotherapeutic drug content compared to doxorubicin alone $(P<0.01)$. Adsorption of doxorubicin to unmodified PLGA nanoparticles (PLGA-doxorubicin) improved the tumor uptake of the chemotherapeutic agent by 1.5 -fold $(P<0.05)$.

\section{Body weights of intact animals}

There were no changes in body weights in any of the xenografted animals (control or drug-exposed), in these short-term studies (results not shown).

\section{Discussion}

Integrin $\alpha v \beta 3$ is generously expressed in the plasma membrane of cancer cells and of dividing endothelial cells, and its extracellular domain contains a receptor or target for thyroid hormone analogs. ${ }^{31-33}$ This receptor provides multiple downstream inputs into the control of cancer cell proliferation and survival pathways, as well as angiogenesis. Tetrac is a naturally occurring analog of L-thyroxine $\left(\mathrm{T}_{4}\right)$ that has been shown to block the binding of thyroxine to the integrin, as well as the actions of 3,3',5-triiodo-L-thyronine $\left(\mathrm{T}_{3}\right) .^{31}$ The latter is the major intracellular agonist form of thyroid hormone. We covalently bound tetrac via a diaminopropane linker to nanoparticulate PLGA to limit the access of tetrac to the intracellular space and thus to concentrate its activity at $\alpha v \beta 3$. This tetrac formulation (NDAT, Nanotetrac) is an effective anticancer agent in vitro and in xenografts. ${ }^{29,34-37}$ The reformulation has a panel of antitumor and antiangiogenic actions beyond what might be expected simply from the inhibition of the binding of $\mathrm{T}_{4}$ and $\mathrm{T}_{3}$ by the integrin. ${ }^{31,32}$

The tissue distribution of the integrin encouraged the development of a second function for NDAT - with its attendant large PLGA nanoparticle - namely, as a delivery moiety for existing generic cancer chemotherapeutic agents to tumors and their supporting vasculature. ${ }^{13}$ The goal of the delivery system is to achieve increased anticancer drug content within tumors and to reduce systemic toxicity. Evidence presented in this article and in a companion article on cisplatin delivery ${ }^{23}$ validates this concept. We show here that the loading with paclitaxel or doxorubicin of the PLGA nanoparticle covalently linked to NDAT resulted in a 5-fold increase in the tumor content of paclitaxel and a 2.3-fold increase in tumor doxorubicin compared to conventional drug administration. We also found that encapsulating the antitumor drugs in unmodified PLGA, ie, PLGA that is not attached to tetrac and thus is not a tumor-targeting system, did provide modest increases in the tumor uptake of drug. Such PLGA encapsulation will prolong the half-life of the drug in the circulation.

There was improved tumor response to paclitaxel delivered by NDAT in pancreatic cancer. In addition to the greater tumor shrinkage achieved by NDAT-paclitaxel as compared to paclitaxel or PLGA-paclitaxel, a clear trend in the reduction in tumor cell viability (bioluminescence signal intensity) measured with IVIS was shown. However, because of the small tumor size, data did not approach $P<0.05$. Breast cancer xenografts proved to be very responsive to doxorubicin, regardless of the method by which the drug was administered. In the companion article in which the tumor delivery of cisplatin by NDAT was studied, we also found a 5-fold enhancement of tumor content of drug, compared to conventionally administered cisplatin. ${ }^{23}$ The multifold increase in the tumor content of each of these widely used anticancer drugs supports the existence of the cancer-targeting property of NDAT. ${ }^{31,32}$

NDAT (Nanotetrac), alone, is an anticancer agent, but the dose of NDAT $(0.3 \mathrm{mg} / \mathrm{kg}$ daily) used in the current studies to deliver generic chemotherapeutic agents was suboptimal in terms of NDAT chemotherapeutic efficacy. ${ }^{38}$ Thus, the antitumor effectiveness measured in this study examines primarily the efficiency of NDAT in terms of delivery of paclitaxel and doxorubicin. While we did not intend to achieve additive or synergistic antitumor effects of NDAT with the other agents, such additive effects may exist. ${ }^{38}$ Antitumor effectiveness of doxorubicin and paclitaxel in the current studies was verified by volume measurements of orthotopic xenografts of breast cancer or by IVIS scanning of the orthotopic xenografts of pancreatic cancer. IVIS scanning, in this study, also provided verification of the loss of viability of cells within the orthotopic tumors.

Studied at drug levels higher than those employed in the current studies, NDAT (Nanotetrac) may also increase the cellular residence time of chemotherapeutic agents, ${ }^{26}$ perhaps by inhibiting the activity of the P-gp efflux system. ${ }^{27}$ It is possible that the suboptimal dosing of NDAT in the current experiments may have been sufficient to enhance tumor retention time and antitumor efficacy of locally delivered paclitaxel and doxorubicin.

\section{Conclusion}

Covalently linked to tetrac, the PLGA nanoparticle of NDAT is a drug delivery system for tumors expressing plasma 
membrane integrin $\alpha v \beta 3$ with its high-affinity cell-surface target for tetrac. In the current study, we have demonstrated the feasibility of delivering paclitaxel and doxorubicin via NDAT to, respectively, pancreatic and breast cancer xenografts. The system achieved intratumoral concentrations of doxorubicin and paclitaxel that are 2.3- to 5-fold higher than via the conventional route of the administration of these agents, as well as improved antitumor efficacy.

\section{Acknowledgment}

This work was supported in part by a grant from NanoPharmaceuticals LLC (Rensselaer, NY, USA).

\section{Disclosure}

The coauthors Paul J Davis and Shaker A Mousa are stockholders in NanoPharmaceuticals LLC that is commercially developing NDAT, and Paul J Davis is an officer of the company. Kelly A Keating is paid as a consultant by NanoPharmaceuticals LLC. The other authors report no conflicts of interest in this work.

\section{References}

1. Matsusaka S, Lenz HJ. Pharmacogenomics of fluorouracil-based chemotherapy toxicity. Expert Opin Drug Metab Toxicol. 2015; 11(5):811-821.

2. Chan ES, Cronstein BN. Mechanisms of action of methotrexate. Bull Hosp Jt Dis. 2013;71(suppl 1):S5-S8.

3. Rivankar $\mathrm{S}$. An overview of doxorubicin formulations in cancer therapy. J Cancer Res Ther. 2014;10(4):853-858.

4. Barbuti AM, Chen ZS. Paclitaxel through the ages of anticancer therapy: exploring its role in chemoresistance and radiation therapy. Cancers. 2015;7(4):2360-2371.

5. Dilruba S, Kalayda GV. Platinum-based drugs: past, present and future. Cancer Chemother Pharmacol. 2016;77(6):1103-1124.

6. Ulbrich K, Hola K, Subr V, Bakandritsos A, Tucek J, Zboril R. Targeted drug delivery with polymers and magnetic nanoparticles: covalent and noncovalent approaches, release control, and clinical studies. Chem Rev. 2016;116(9):5338-5431.

7. Arosio D, Casagrande C. Advancement in integrin facilitated drug delivery. Adv Drug Deliv Rev. 2016;97:111-143.

8. Linton SS, Sherwood SG, Drews KC, Kester M. Targeting cancer cells in the tumor microenvironment: opportunities and challenges in combinatorial nanomedicine. Wiley Interdiscip Rev Nanomed Nanobiotechnol. 2016;8(2):208-222.

9. Oberoi RK, Parrish KE, Sio TT, Mittapalli RK, Elmquist WF, Sarkaria JN. Strategies to improve delivery of anticancer drugs across the blood-brain barrier to treat glioblastoma. Neuro Oncol. 2016;18(1): 27-36.

10. Soudy R, Byeon N, Raghuwanshi Y, Ahmed S, Lavasanifar A, Kaur K. Engineered peptides for applications in cancer targeted drug delivery and tumor detection. Mini Rev Med Chem. Epub 2016 Feb 19.

11. Yang Y, Yu C. Advances in silica based nanoparticles for targeted cancer therapy. Nanomedicine. 2016;12(2):317-332.

12. Davis PJ, Goglia F, Leonard JL. Nongenomic actions of thyroid hormone. Nat Rev Endocrinol. 2016;12(2):111-121.

13. Bharali DJ, Yalcin M, Davis PJ, Mousa SA. Tetraiodothyroacetic acid-conjugated PLGA nanoparticles: a nanomedicine approach to treat drug-resistant breast cancer. Nanomedicine (Lond). 2013;8(12): 1943-1954.
14. van der Meel R, Vehmeijer LJ, Kok RJ, Storm G, van Gaal EV. Ligandtargeted particulate nanomedicines undergoing clinical evaluation: current status. Adv Drug Deliv Rev. 2013;65(10):1284-1298.

15. Iyer AK, Singh A, Ganta S, Amiji MM. Role of integrated cancer nanomedicine in overcoming drug resistance. Adv Drug Deliv Rev. 2013;65(13-14):1784-1802.

16. Alibolandi M, Abnous K, Hadizadeh F, et al. Dextran-poly lactide-coglycolide polymersomes decorated with folate-antennae for targeted delivery of docetaxel to breast adenocarcinima in vitro and in vivo. J Control Release. 2016;241:45-56.

17. Fasehee H, Dinarvand R, Ghavamzadeh A, et al. Delivery of disulfiram into breast cancer cells using folate-receptor-targeted PLGA-PEG nanoparticles: in vitro and in vivo investigations. J Nanobiotechnology. 2016;14:32.

18. Chen Z, Patel JM, Noble PW, et al. A lupus anti-DNA autoantibody mediates autocatalytic, targeted delivery of nanoparticles to tumors. Oncotarget. 2016;7(37):59965-59975.

19. Zhang X, Li J, Yan M. Targeted hepatocellular carcinoma therapy: transferrin modified, self-assembled polymeric nanomedicine for codelivery of cisplatin and doxorubicin. Drug Dev Ind Pharm. 2016;42(10): 1590-1599.

20. Di-Wen S, Pan GZ, Hao L, et al. Improved antitumor activity of epirubicin-loaded CXCR4-targeted polymeric nanoparticles in liver cancers. Int J Pharm. 2016;500(1-2):54-61.

21. Zhang X, Wang Q, Qin L, et al. EGF-modified mPEG-PLGA-PLL nanoparticle for delivering doxorubicin combined with Bcl-2 siRNA as a potential treatment strategy for lung cancer. Drug Deliv. 2016; 23(8):2936-2945

22. Wang C, Su L, Wu C, Wu J, Zhu C, Yuan G. RGD peptide targeted lipid-coated nanoparticles for combinatorial delivery of sorafenib and quercetin against hepatocellular carcinoma. Drug Dev Ind Pharm. 2016;42(12):1938-1944.

23. Sudha T, Bharali DJ, Yalcin M, et al. Targeted delivery of cisplatin to tumor xenografts via the nanoparticle component of nano-diaminotetrac. Nanomedicine (Lond). 2017;12(3):195-205.

24. Jin $\mathrm{C}, \mathrm{Li} \mathrm{H}, \mathrm{He} \mathrm{Y}$, et al. Combination chemotherapy of doxorubicin and paclitaxel for hepatocellular carcinoma in vitro and in vivo. $J$ Cancer Res Clin Oncol. 2010;136(2):267-274.

25. Wang Y, Zhang H, Hao J, Li B, Li M, Xiuwen W. Lung cancer combination therapy: co-delivery of paclitaxel and doxorubicin by nanostructured lipid carriers for synergistic effect. Drug Deliv. 2016;23(4): 1398-1403.

26. Rebbaa A, Chu F, Davis FB, Davis PJ, Mousa SA. Novel function of the thyroid hormone analog tetraiodothyroacetic acid: a cancer chemosensitizing and anti-cancer agent. Angiogenesis. 2008;11(3):269-276.

27. Davis PJ, Incerpi S, Lin HY, Tang HY, Sudha T, Mousa SA. Thyroid hormone and p-glycoprotein in tumor cells. Biomed Res Int. 2015;2015:168427.

28. Siddiqui IA, Bharali DJ, Nihal M, et al. Excellent anti-proliferative and pro-apoptotic effects of (-)-epigallocatechin-3-gallate encapsulated in chitosan nanoparticles on human melanoma cell growth both in vitro and in vivo. Nanomedicine. 2014;10(8):1619-1626.

29. Yalcin M, Bharali DJ, Lansing L, et al. Tetraidothyroacetic acid (tetrac) and tetrac nanoparticles inhibit growth of human renal cell carcinoma xenografts. Anticancer Res. 2009;29(10):3825-3831.

30. Israel M, Pegg WJ, Wilkinson PM, Garnick MB. Liquid chromatographic analysis of adriamycin and metabolites in biological fluids. J Liq Chromatogr. 1978;1(6):795-809.

31. Davis PJ, Davis FB, Mousa SA, Luidens MK, Lin HY. Membrane receptor for thyroid hormone: physiologic and pharmacologic implications. Annu Rev Pharmacol Toxicol. 2011;51:99-115.

32. Davis PJ, Glinsky GV, Lin HY, et al. Cancer cell gene expression modulated from plasma membrane integrin $\alpha v \beta 3$ by thyroid hormone and nanoparticulate tetrac. Front Endocrinol (Lausanne). 2014;5:240.

33. Bergh JJ, Lin HY, Lansing L, et al. Integrin $\alpha v \beta 3$ contains a cell surface receptor site for thyroid hormone that is linked to activation of mitogenactivated protein kinase and induction of angiogenesis. Endocrinology. 2005;146(7):2864-2871. 
34. Yalcin M, Lin HY, Sudha T, et al. Response of human pancreatic cancer cell xenografts to tetraiodothyroacetic acid nanoparticles. Horm Cancer. 2013;4(3):176-185.

35. Mousa SA, Yalcin M, Bharali DJ, et al. Tetraiodothyroacetic acid and its nanoformulation inhibit thyroid hormone stimulation of non-small cell lung cancer cells in vitro and its growth in xenografts. Lung Cancer. 2012;76(1):39-45.

36. Glinskii AB, Glinsky GV, Lin HY, et al. Modification of survival pathway gene expression in human breast cancer cells by tetraiodothyroacetic acid (tetrac). Cell Cycle. 2009;8(21):3562-3570.
37. Lin HY, Sun M, Tang HY, et al. L-thyroxine vs. 3,5,3'-triiodo-1thyronine and cell proliferation: activation of mitogen-activated protein kinase and phosphatidylinositol 3-kinase. Am J Physiol Cell Physiol. 2009;296(5):C980-C991.

38. Lin HY, Landersdorfer CB, London D, et al. Pharmacodynamic modeling of anti-cancer activity of tetraiodothyroacetic acid in a perfused cell culture system. PLoS Comput Biol. 2011;7(2):e1001073. 


\section{Supplementary materials}

Measurement of the amount of paclitaxel and doxorubicin encapsulated in the

\section{nanoparticles}

Data are shown for the measurement of the amount of doxorubicin encapsulated in the nanoparticles; the method was the same for paclitaxel.

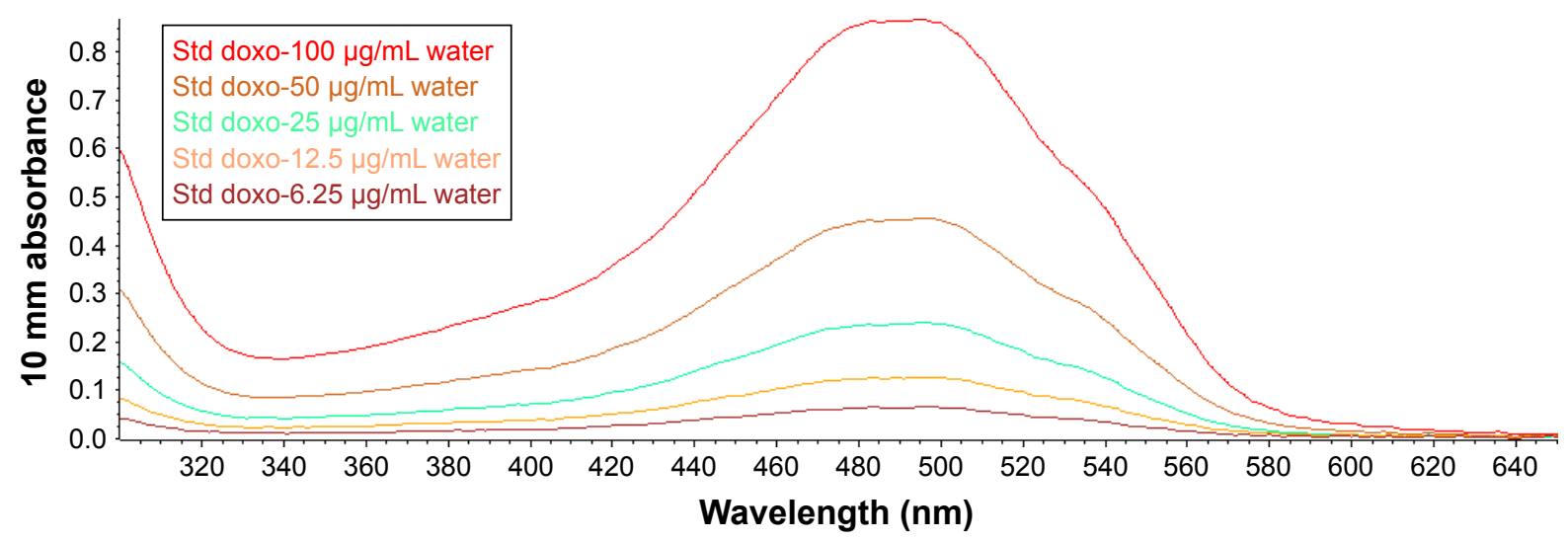

Figure SI UV spectroscopy was used to measure absorbance for a standard curve for concentrations of doxorubicin; absorbance was measured at 500 nm. Abbreviations: doxo, doxorubicin; Std, standard; UV, ultraviolet.

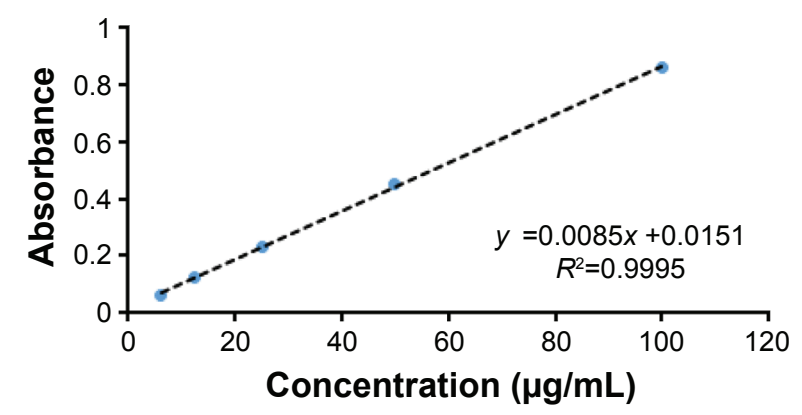

Figure S2 Standard curve for doxorubicin.

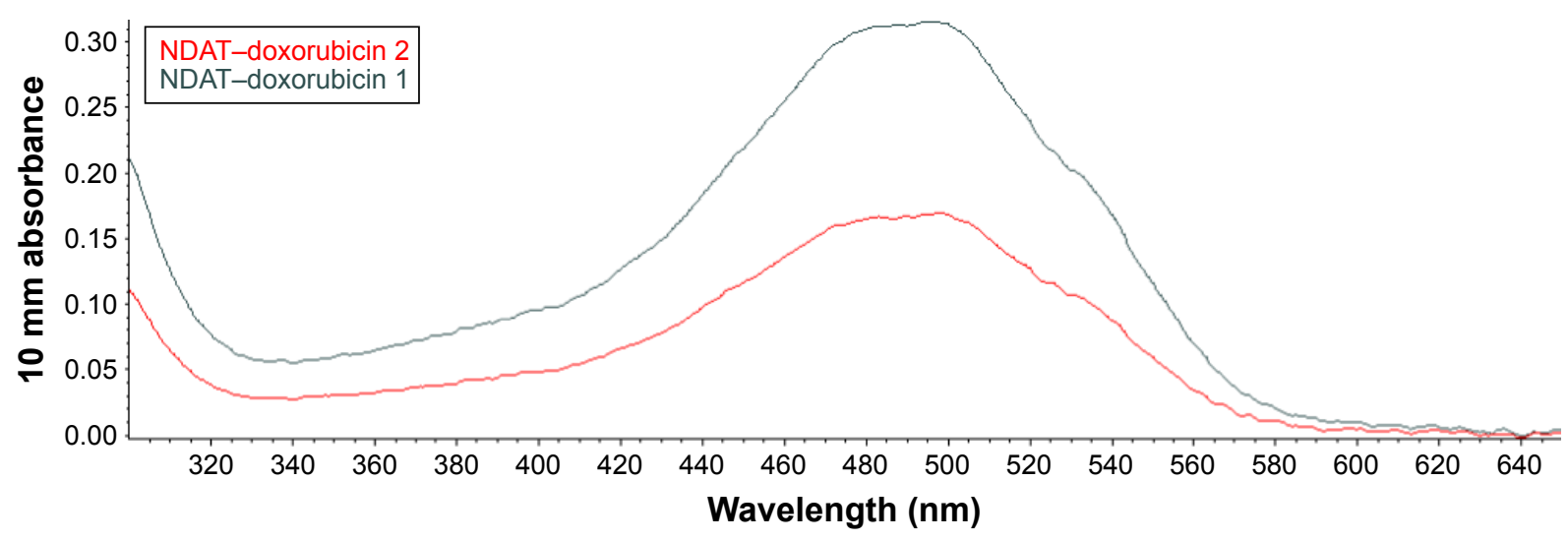

Figure S3 UV spectra for doxorubicin-encapsulated nanoparticles; absorbance was measured at $500 \mathrm{~nm}$.

Abbreviations: NDAT, nano-diamino-tetrac; tetrac, tetraiodothyroacetic acid; UV, ultraviolet. 

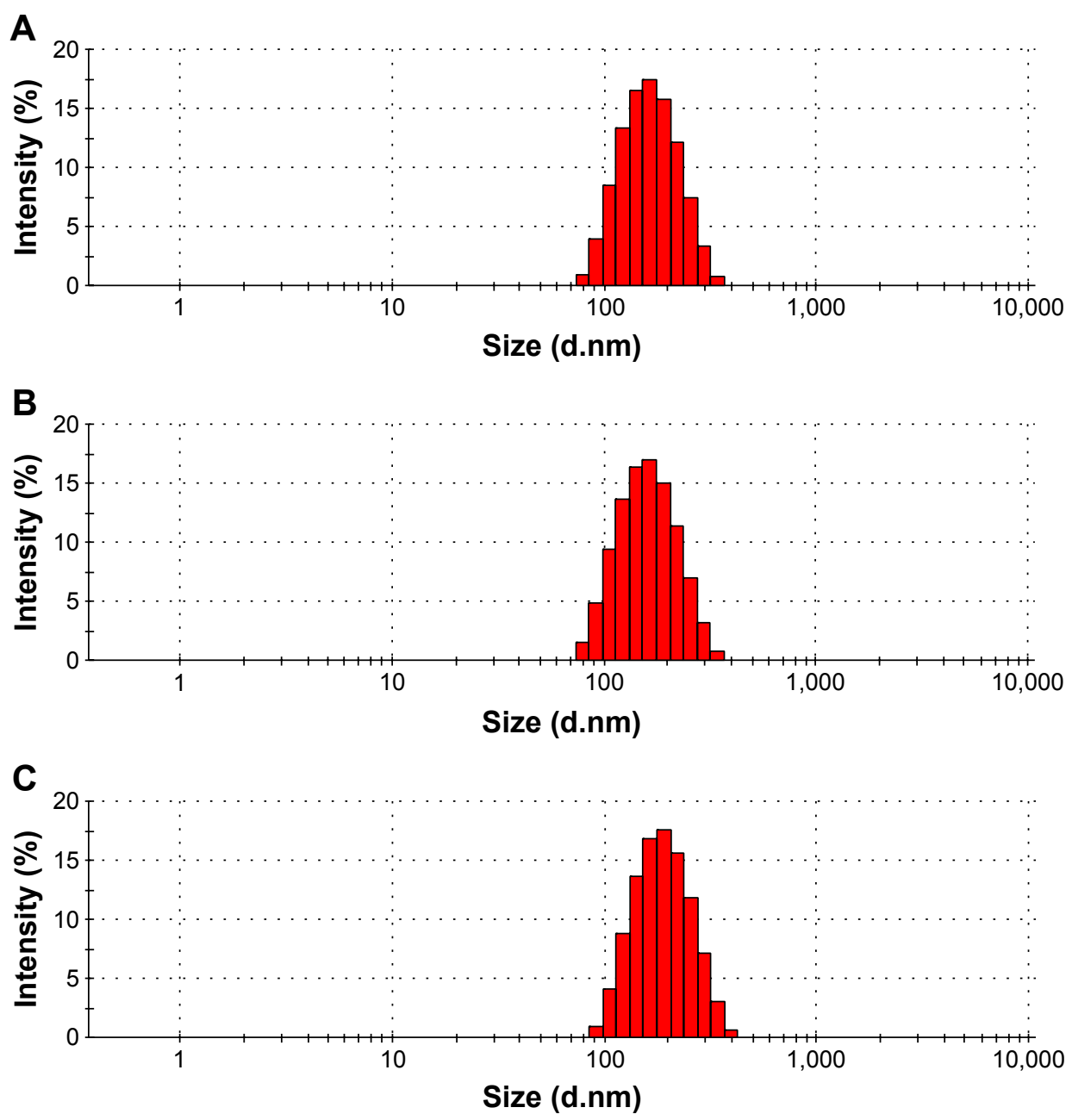

Figure S4 DLS measurements of (A) void PLGA nanoparticles and PLGA nanoparticles encapsulating (B) paclitaxel and (C) doxorubicin. Abbreviations: DLS, dynamic light scattering; PLGA, poly(lactic-co-glycolic acid).

\section{Publish your work in this journal}

The International Journal of Nanomedicine is an international, peerreviewed journal focusing on the application of nanotechnology in diagnostics, therapeutics, and drug delivery systems throughou the biomedical field. This journal is indexed on PubMed Central, MedLine, CAS, SciSearch ${ }^{\circledR}$, Current Contents ${ }^{\circledR} /$ Clinical Medicine,
Journal Citation Reports/Science Edition, EMBase, Scopus and the Elsevier Bibliographic databases. The manuscript management system is completely online and includes a very quick and fair peer-review system, which is all easy to use. Visit http://www.dovepress.com/ testimonials.php to read real quotes from published authors.

\footnotetext{
Submit your manuscript here: http://www.dovepress.com/international-journal-of-nanomedicine-journal
} 